2002s-74

\title{
Opportunity Costs, Competition, and Firm Selection
}

\author{
Gamal Atallah
}

\begin{tabular}{c}
\hline Série Scientifique \\
Scientific Series
\end{tabular}

\section{Montréal}

Juillet 2002

(C) 2002 Gamal Atallah. Tous droits réservés. All rights reserved. Reproduction partielle permise avec citation du document source, incluant la notice (C)

Short sections may be quoted without explicit permission, if full credit, including $@$ notice, is given to the source.
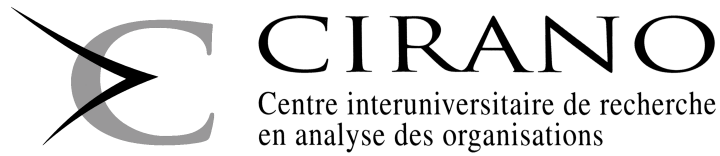

Centre interuniversitaire de recherche en analyse des organisations 


\section{CIRANO}

Le CIRANO est un organisme sans but lucratif constitué en vertu de la Loi des compagnies du Québec. Le financement de son infrastructure et de ses activités de recherche provient des cotisations de ses organisationsmembres, d'une subvention d'infrastructure du ministère de la Recherche, de la Science et de la Technologie, de même que des subventions et mandats obtenus par ses équipes de recherche.

CIRANO is a private non-profit organization incorporated under the Québec Companies Act. Its infrastructure and research activities are funded through fees paid by member organizations, an infrastructure grant from the Ministère de la Recherche, de la Science et de la Technologie, and grants and research mandates obtained by its research teams.

\section{Les organisations-partenaires / The Partner Organizations}

-École des Hautes Études Commerciales

-École Polytechnique de Montréal

-Université Concordia

-Université de Montréal

-Université du Québec à Montréal

-Université Laval

-Université McGill

-Ministère des Finances du Québec

-MRST

-Alcan inc.

- AXA Canada

-Banque du Canada

-Banque Laurentienne du Canada

- Banque Nationale du Canada

- Banque Royale du Canada

-Bell Canada

-Bombardier

-Bourse de Montréal

-Développement des ressources humaines Canada (DRHC)

-Fédération des caisses Desjardins du Québec

-Hydro-Québec

-Industrie Canada

-Pratt \& Whitney Canada Inc.

-Raymond Chabot Grant Thornton

-Ville de Montréal

Les cahiers de la série scientifique (CS) visent à rendre accessibles des résultats de recherche effectuée au CIRANO afin de susciter échanges et commentaires. Ces cahiers sont écrits dans le style des publications scientifiques. Les idées et les opinions émises sont sous l'unique responsabilité des auteurs et ne représentent pas nécessairement les positions du CIRANO ou de ses partenaires.

This paper presents research carried out at CIRANO and aims at encouraging discussion and comment.

The observations and viewpoints expressed are the sole responsibility of the authors. They do not necessarily represent positions of CIRANO or its partners. 


\title{
Opportunity Costs, Competition, and Firm Selection
}

\author{
Gamal Atallah*
}

\section{Résumé / Abstract}

Coûts d'opportunité, concurrence et survie des entreprises. La présente étude remet en question l'hypothèse économique courante voulant que les agents économiques en situation de concurrence aient des niveaux d'utilité de réserve identiques, et que lorsque des différences dans les coûts d'opportunité existent, elles puissent être incorporées dans les coûts fixes. Les coûts d'opportunité sont endogénisés en les reliant au niveau d'efficacité dans l'activité courante. On examine l'effet de cette interchangeabilité des qualifications dans une industrie en concurrence à la Cournot avec entrée potentielle. On montre que les firmes inefficaces ont tendance à remplacer les firmes efficaces lorsque la corrélation entre l'efficacité courante et les coûts d'opportunité est élevée, et lorsque les coûts fixes de changer d'industrie sont élevés. De plus, à long terme les firmes ayant des coûts intermédiaires induisent la sortie des firmes ayant des coûts très bas ou très élevés.

The paper questions the standard economic assumptions that competing economic agents have identical reservation utility levels, and that when differences in opportunity costs exit, they can be conveniently represented by fixed costs. Opportunity costs are endogenized by linking them to current efficiency. The effect of this interchangeability of skills is studied in the context of the effect of entry on firm selection in a Cournot setting. It is found that inefficient firms are more likely to crowd out efficient ones when the relationship between current efficiency and opportunity costs is strong, and when the fixed costs of changing markets are high. Moreover, in the long run firms with intermediate cost levels are likely to induce the exit of low and high cost firms.

Mots clés : Entrée, Sortie, Efficacité, Survie des entreprises.

Keywords: Entry, Exit, Efficiency, Firm selection.

Codes JEL : D43, L13

\footnotetext{
* CIRANO, Department of Economics, University of Ottawa, E-mail: gatallah@uottawa.ca.
} 


\section{Introduction}

It is a common assumption in the economic literature that when many agents are involved in a given activity, they have the same level of reservation utility, and this level of utility is generally normalized to zero. For instance, in bargaining games, an agent would never accept an exchange yielding a negative utility. In competition between firms, each firm must realize non-negative profits and, under free entry, the zero-profit condition determines the number of firms in the industry. All agents are assumed to have similar reservation utilities, irrespective of their relative efficiencies.

This assumption does not account for the fact that skills may be interchangeable between activities. For instance, an agent who is very efficient in performing activity A may also be very efficient in performing activity B. This would generate a situation where efficiency is positively correlated with reservation utility. In a model of competition between firms, for instance, the zeroprofit condition would no longer determine the number (and composition) of firms in the industry, given that the most efficient firms would exit the industry long before profits are driven down to zero.

Fixed costs are often used as a proxy for opportunity costs. It is true that fixed costs can represent difficult to measure opportunity costs. However, this asserted equivalence between fixed costs and opportunity costs has kept in the shadow a major difference between them: that economics cannot tell us much in general about (technologically determined) fixed costs, but should be able to tell us more about opportunity costs. The aim of this paper is to put a structure on these opportunity costs, by relating them to efficiency.

The idea that reservation profits are related to efficiency can alter standard economic analysis in many ways. The modelling of endogenous reservation profits is most important when skills are easily interchangeable between industries, so that efficiency and high profits in one sector guarantee high profits in adjacent, but different, sectors. In this paper I examine the effect of this relationship on the entry and exit of firms. When very efficient firms have high reservation profits (because skills are highly interchangeable between industries), does increased competition necessarily lead to the survival of the fittest? Facing an intensification of competition, low cost firms may prefer to exit the market and move to other activities where competition is less intense. It 
remains true that competition ultimately drives profits (net of opportunity costs) to zero, but it does not automatically result in the survival of the fittest. The equivalence between zero profits and survival of the fittest does not necessarily hold when reservation profits are correlated with efficiency.

Equivalently, the problem can be seen as one of intense competition acting as a deterrent for entry by efficient firms. A competent entrepreneur with highly innovative skills (and therefore with high opportunity costs, because he/she can be successful in many industries) considering to enter one of a number of industries, will prefer a less competitive industry to a more competitive one. Hence competition does not necessarily attract the best players, actually it may attract the worse, those who have low opportunity costs because they are inefficient.

I study this problem in a Cournot setting, with incumbents and a potential entrant. The potential entrant decides whether to enter or not; then, based on its decisions, each incumbent decides whether to stay in the market or to exit, taking into account its post-entry profits and its reservation profits. The main question is: when do efficient firms crowd out inefficient ones, and when does the opposite occur? Contrarily to what would happen if all firms had equal reservation profits, the inefficient firms will not necessarily be the first to exit. Endogenous opportunity costs affect not only the size, but also the composition of the industry. The model will not say much about the number of firms that exit; rather, the focus will be on the identity of the exiting firms. The model therefore studies the relationship between reservation profits on the one hand, and the identity of the exiting firms on the other hand.

It is found that entry by a firm may result in the exit of a more or a less efficient firm, depending on the relationship between current profits and opportunity costs. When opportunity costs are highly correlated with current profits, inefficient firms will crowd out more efficient ones, since the efficient firms, who have high current profits and hence high opportunity costs, gain more by leaving the market following entry by an inefficient firm. Moreover, that inefficient firm will prefer to enter, given that its opportunity costs of entering are low (because of the high correlation between profits in that industry and opportunity costs). The opposite occurs when the correlation between current profits and opportunity costs is weak: efficient firms will crowd out inefficient ones.

The second dimension of opportunity costs which affects firm selection is the fixed cost of 
changing markets. When this fixed cost is high, inefficient firms tend to crowd out the more efficient firms. In that case, the profits high cost firms would make on other markets are not sufficient to compensate for the cost of exiting the current market and entering an alternative market. At the same time, the low cost firm, because of transferable skills, can achieve high profits on the other market, and hence is more willing to exit the current market when competition intensifies. The opposite occurs when the fixed cost of changing markets is low: efficient firms tend to crowd out inefficient ones.

Moreover, because the bounds of the critical parameter values (of the opportunity costs function) determining when entry crowds out the most efficient firm and the most inefficient firm form a small interval, the model predicts that in a dynamic setting firms with intermediate costs would crowd out the most efficient and the least efficient firms, resulting in a long term equilibrium where most of the remaining firms have "intermediate" levels of efficiency.

While no work I am aware of in the economic literature deals with the relation between opportunity costs and efficiency explicitly, or the impact of this relation on the entry and exit of firms, there is a large literature on firm selection, studying which firms survive a decline in demand. Many of those studies predict that competition does not necessarily select the best firms or the best plants.

Fudenberg and Tirole (1986) study selection in a setting of incomplete information about the rival's cost, and find that with symmetric expectations the less efficient firm exits. In a model of industry life-cycle, Londregan (1986) finds that with the possibility of reentry and with positive reentry costs, small firms stay in the market while larger firms exit. Fine and Li (1986) and Huang and $\mathrm{Li}$ (1986) show that when demand declines probabilistically, there are equilibria where smaller firms stay in the market longer than larger firms. Dierickx et al. (1991) find that the order of exit of firms depends on the way in which demand shrinks (population shrinkage, decline in willingness to pay, parallel inward shift). Lippman et al. (1991) demonstrate that demand uncertainty can produce heterogeneity in the equilibrium employment of production technologies and can permit the coexistence of producers exhibiting different minimum average costs. Garella and Richelle (1999) study the problem of firm selection in an infinite horizon supergame. They find that the exiting firms are those with higher average cost functions whenever reentry is costless while, 
whenever reentry is unprofitable, the exiting firms are those with lower marginal cost functions. Gromb et al. (1997) derive sufficient conditions for competition to select the most efficient firm in a dynamic entry deterrence framework.

Some studies have focussed on the capacity of firms as an instrument of firm selection. Ghemawat and Nalebuff (1985) find that in a duopolistic declining industry where the capacity choice is all or nothing, the largest firms exit first. The intuition is that the smaller firm can be a profitable monopolist for a longer period in a declining industry. The cost difference for the large firm to reverse that result is found to be substantial. The result extends to continuous capacity adjustment (Ghemawat and Nalebuff, 1990) because the larger firm has greater incentives to reduce its capacity, given that it benefits more from increasing prices. Whinston (1988) extends the framework of Ghemawat and Nalebuff to the case where firms have multiplant operations, and does not find support for their empirical predictions that with single plants duopolists, the larger duopolist exits first when facing a declining industry. Reynolds (1988) finds that the larger firm begins closing its plants before the smaller firm when the cost differences are not too large.

Empirically, there is some evidence of industries where selection does not always conform to the predictions of the standard economic model. Ghemawat and Nalebuff(1990) report empirical evidence that in a number of industries, in the face of declining demand, larger firms have tended to reduce capacity more than smaller firms did (and more than proportionally to their market share). The examples come from the synthetic soda ash, the U. K. steel castings, and the U. S. integrated steel-making industries. Ghemawat (1985) finds over the 1967-77 period in 294 (four-digit) U. S. manufacturing industries, declines in demand were associated with decreases in concentration, which is consistent with the idea that large firms suffer more from the intensification in competition than smaller firms. Libereman (1990), using data on 30 chemical products, finds that large multiplant firms are more likely to close individual plants.

This paper goes in the direction of showing that the transferability of skills also can result in the survival of inefficient firms, and, furthermore, in the crowding out of low cost firms by high cost ones. Although there are numerous cases where competition has selected the most efficient firms, the examples of inefficient selection provided above are sufficient to motivate investigating theoretical circumstances under which selection does not work. 
The model is presented in section 2 and solved in section 3. Section 4 concludes.

\section{The model}

There are $\mathrm{n}>1$ firms producing a homogeneous output. Firms face a linear inverse demand $\mathrm{p}=\mathrm{A}-\mathrm{Y}$, with $\mathrm{Y}=\sum_{\mathrm{i}=1}^{\mathrm{n}} \mathrm{y}_{\mathrm{i}}$. Let $\mathrm{c}_{\mathrm{i}}$ denote the (constant) marginal cost of firm $\mathrm{i}, \mathrm{i} \in\{1,2, \ldots, \mathrm{n}\}$, and, without loss of generality, let the firm with the lowest marginal cost among incumbents be firm 1 , and the firm with the highest marginal cost among incumbents be firm $\mathrm{n}$. To simplify the exposition of the results, it is assumed that no two incumbents have the same costs: $\mathrm{c}_{1}<\mathrm{c}_{2}<\ldots<\mathrm{c}_{\mathrm{n}}$. It is also assumed that the potential entrant's cost is equal to the cost of one of the incumbents. The importance of this assumption for the tractability of the results will become clear later. The costs of incumbents are such that each incumbent produces strictly positive output before entry, and that all remaining firms after entry, as well as the potential entrant (if entry occurs) produce strictly positive output.

Firms' reservation profits are related to their efficiency, with the most efficient firms having higher reservation profits. Ideally, one would want to link reservation profits directly to costs, with $\bar{\pi}^{\prime}(\mathrm{c})<0$, where $\bar{\pi}$ denotes reservation profits. However, without a firm theoretical basis as to how reservation profits are related to costs, it is difficult to say more about the function $\bar{\pi}(\mathrm{c})$. Given the difficulty of linking reservation profits directly to costs, we link them to current profits, and therefore indirectly to costs. Namely, we use a function $\bar{\pi}\left(\pi_{\mathrm{ib}}\right)$, where $\pi_{\mathrm{ib}}$ is the profit of firm i before entry, such that $\pi^{\prime}\left(\pi_{b}\right)>0$. Given that $\pi_{b}{ }^{\prime}(c)<0$ (this will become obvious later), the function $\pi\left(\pi_{b}(c)\right.$ ) satisfies the basic property mentioned above. More specifically, we use the functional form

$$
\bar{\pi}_{\mathrm{i}}=\alpha \pi_{\mathrm{ib}}-\mathrm{F}
$$

with $\alpha, \mathrm{F}>0$ and parameters are such that $\bar{\pi}_{\mathrm{i}}>0$ for all $\mathrm{i}$.

$\alpha$ represents the degree of interchangeability of skills between industries. The higher $\alpha$, the more interchangeable skills are, and the higher is the correlation between reservation profits and current profits. $\mathrm{F}$ is a fixed term which represents the fixed cost of changing markets. $\alpha$ and $\mathrm{F}$ are common to all firms.

This functional form represents a generalization of two functional forms which are natural to study in the analysis of the relationship between current profits and reservation profits. The first 
form is $\bar{\pi}_{\mathrm{i}}=\alpha \pi_{\mathrm{ib}}$ (with $\mathrm{F}=0$ ) where reservation profits are a constant fraction of current profits. The second form is $\bar{\pi}_{\mathrm{i}}=\pi_{\mathrm{ib}}-\mathrm{F}$ (with $\alpha=1$ ) where the difference between current profits and reservation profits is the same for all firms.

Once reservation profits are derived as above, they are treated as a constant: they do not change with changes in the market. Reservation profits depend on conditions prevailing in other markets, and these conditions are assumed to remain unchanged. The only reason why they are made to depend (initially) on the conditions in the current market is to establish a monotonic relationship between efficiency and reservation profits. Hence, when a firm enters the market, this clearly changes the level of profits of firms, but does not change reservation profits, which are treated as constants. Moreover, because it is this monotonicity between efficiency and reservation profits which matters for the model, the initial dependence of reservation profits on current profits does not reduce in any way the generality of the model.

Note that, in this paper, the term "lowest cost firm" or "most efficient firm" refers to the firm with the lowest production cost; it does not mean that that firm has the lowest sum of production and opportunity costs. Furthermore, to emphasize the distinction made in this paper between fixed costs and opportunity costs, we refer to the latter as opportunity costs, not fixed costs. Moreover, although in some of the literature reviewed above the selection process is in terms of large vs. small firms, rather than efficient vs. inefficient firms, in this paper the differences in size stem from differences in efficiency, and hence -as is standard in Industrial Organization-, large size is associated with a higher degree of efficiency.

The game has three stages. In the first stage incumbents compete in Cournot. In the second stage a potential entrant decides whether to enter or not, and executes its decision. In the third stage, after observing the behaviour of the potential entrant, each incumbent considers whether it wants to stay in the market or to exit, and executes its decision. ${ }^{2}$ Entry and exit decisions, as well as firms' costs, are common knowledge.

In the first stage all incumbents compete in Cournot. The profits of incumbent $\mathrm{i}$ before entry

\footnotetext{
${ }^{2}$ In fact there could be a fourth stage to the game, where Cournot competition takes place once all the entry and exit decisions have been taken and implemented. However, given that the focus of the model is on entry and exit decisions, adding such a stage would not add anything to the model.
} 
are $\pi_{\mathrm{ib}}=\left(\mathrm{p}(\mathrm{Y})-\mathrm{c}_{\mathrm{i}}\right) \mathrm{y}_{\mathrm{i}}$. Competition in Cournot in the first stage results in the following profit for firm i:

$$
\pi_{i b}=\frac{\left(A+\sum_{x \neq i}^{n} c_{x}-n c_{i}\right)^{2}}{(n+1)^{2}}
$$

It is assumed that the conditions for the existence and unicity of the equilibrium are satisfied. The usefulness of the first stage is that it yields the profits of firms before entry, which determine firms' reservation profits. The reservation profits of firm $i$ are

$$
\begin{aligned}
\bar{\pi}_{i} & =\alpha \pi_{i b}-F \\
& =\alpha \frac{\left(A+\sum_{x \neq i}^{n} c_{x}-n c_{i}\right)^{2}}{(n+1)^{2}}-F
\end{aligned}
$$

It will be sufficient for now to mention that $\pi_{\mathrm{ib}}>\bar{\pi}_{\mathrm{i}}$ for all $\mathrm{i}$. This will be shown to hold in equilibrium. This is essential for the initial Cournot equilibrium to be stable, otherwise some firms may prefer to exit at the outset.

In the second stage a potential entrant considers whether to enter the market or not. If it enters, the entrant expects to realize profits $\pi_{\text {ea }}$, which are the profits after entry (taking the presence of the incumbents as given):

$$
\pi_{e a}=\frac{\left(A+\sum_{x=1}^{n} c_{x}-(n+1) c_{e}\right)^{2}}{(n+2)^{2}}
$$

If it does not enter, the potential entrant realizes its reservation profits. Given that the potential entrant is identical to one of the incumbents, it has the same reservation profits as that incumbent. Namely, if the incumbent that is identical to the potential entrant is firm $i$ with $\operatorname{cost} c_{i}=c_{e}$ and with reservation profits $\bar{\pi}_{\mathrm{i}}=\alpha \pi_{\mathrm{ib}}-\mathrm{F}$, the reservation profits of the entrant will be $\bar{\pi}_{\mathrm{e}}=\bar{\pi}_{\mathrm{i}}$. The potential entrant will enter if the profits it expects to realize on the market (assuming that no firm exits) are 
higher than its reservation profits, $\pi_{\mathrm{ea}} \geq \bar{\pi}_{\mathrm{e}}$. Therefore, the entry decision will be contingent on $\alpha$ and F.

It is now clear why it was assumed that the potential entrant is identical to one of the incumbents: this allows us to determine $\bar{\pi}_{\mathrm{e}}$. If there was no incumbent that is identical to the potential entrant, the model would not provide a way of determining $\bar{\pi}_{\mathrm{e}}$.

In the third stage each incumbent considers whether it will stay in the market, after observing whether the potential entrant has entered or not, and executes its decision. Firms base their exit decisions on the profits they expect to realize after the potential entrant has entered or not. The profits of incumbent $i$ after entry are

$$
\pi_{i \alpha}^{e}=\frac{\left(A+\sum_{x \neq i}^{n} c_{x}-(n+1) c_{i}+c_{e}\right)^{2}}{(n+2)^{2}}
$$

$\pi_{\mathrm{i} a}^{\mathrm{e}}$ represents the profits of incumbent $\mathrm{i}$ after entry of a firm with cost $\mathrm{c}_{\mathrm{e}}$. This does not mean that firm e will actually enter. Rather, $\pi_{\mathrm{i} a}^{\mathrm{e}}$ is computed to analyse the behaviour of firm $\mathrm{i}$ if e enters, not to describe the post-entry equilibrium (the superscript e will not always be explicited; to alleviate the notation, it will be used only when it is necessary to refer to the profits of an incumbent after the entry of a specific type of firm). It is straightforward to verify that entry reduces incumbents' profits: $\pi_{\mathrm{ia}}<\pi_{\mathrm{ib}}$ for all $\mathrm{i}$. As explained above, this change in profits does not alter reservation profits, which at this stage are treated as constants.

If entry occurs, incumbent $i$ will exit if $\pi_{\mathrm{ia}} \leq \bar{\pi}_{\mathrm{i}}$. It is possible to find parameters $\alpha$ and $\mathrm{F}$ such that any number of firms (from 0 to $\mathrm{n}$ ) exits. As mentioned in the introduction, the focus of this paper is on the identity of the firms that exit, rather than on their number. In order to focus the analysis, we assume that $\alpha$ and $\mathrm{F}$ are such that there are as few firms as possible, but at least one, such that $\pi_{\mathrm{ia}}=\bar{\pi}_{\mathrm{i}}$. This is done through the choice of $\alpha$ and $\mathrm{F}$. This allows us to relate reservation profits, represented by the couple $(\alpha, \mathrm{F})$, to the identity of the firm(s) that exit(s).

Note that this choice of $\alpha$ and F implies that only one firm will exit. For, if $\pi_{\mathrm{a}}=\bar{\pi}$ for more than one firm, the exit of only one of those firms will cause the condition to become nonbinding for the other firm(s): its exit will result in an increase in $\pi_{\mathrm{a}}$ for the other firm(s), and they now prefer 
to stay in the market.

The equilibrium concept used is Nash. The model does not allow for any strategic behaviour aiming at pre-empting entry when entry is profitable for the entrant. The focus is on the effect of reservation profits on the pattern of entry and exit. While multistage games are usually solved by backward induction to ensure subgame perfection, in this game Nash equilibria and subgame perfect equilibria coincide, hence there is no loss of generality from using the Nash equilibrium and solving the game starting with the first stage.

\section{Analysis}

The incentives for exit relate to the relationship between current profits and reservation profits. Consider any two firms $i$ and $j$, with $c_{i}<c_{j}$. Because $\pi_{i}>\pi_{j}$, firm $i$ can suffer a larger reduction in profits before exiting, hence firm $\mathrm{j}$ may have greater incentives to exit. However, because $\bar{\pi}_{\mathrm{i}}>\bar{\pi}_{\mathrm{j}}$, firm i may hit its reservation profits constraint first, and hence may have greater incentives to exit. Which firm will exit will depend to a great extent on how profits are reduced through entry. The following lemma addresses this question.

Lemma 1. Let $\Delta \pi_{\mathrm{i}} \equiv \pi_{\mathrm{ib}}-\pi_{\mathrm{ia}}$. In an $\mathrm{n}$-firms oligopoly competing a la Cournot and facing a linear demand, for any pairs of incumbents:

i) Entry by a firm induces the largest reduction in the profits of the most efficient incumbent (i.e. $\Delta \pi_{\mathrm{i}}>\Delta \pi_{\mathrm{j}}$ iff $\left.\mathrm{c}_{\mathrm{i}}<\mathrm{c}_{\mathrm{j}}\right)$;

ii) Entry by a firm induces the largest proportional reduction in the profits of the least efficient incumbent (i.e. $\Delta \pi_{\mathrm{i}} / \pi_{\mathrm{ib}}<\Delta \pi_{\mathrm{j}} / \pi_{\mathrm{jb}}$ iff $\mathrm{c}_{\mathrm{i}}<\mathrm{c}_{\mathrm{j}}$ ).

Proof.

i) The reduction in the profits of firm $i$ is

$$
\Delta \pi_{i}=\pi_{i b}-\pi_{i a}=\frac{\left(A+\sum_{x \neq i}^{n} c_{x}-n c_{i}\right)^{2}}{(n+1)^{2}}-\frac{\left(A+\sum_{x \neq i}^{n} c_{x}-(n+1) c_{i}+c_{e}\right)^{2}}{(n+2)^{2}}
$$

The reduction in the profits of firm $j$ is 


$$
\Delta \pi_{j}=\pi_{j b}-\pi_{j a}=\frac{\left(A+\sum_{x \neq j}^{n} c_{x}-n c_{j}\right)^{2}}{(n+1)^{2}}-\frac{\left(A+\sum_{x \neq j}^{n} c_{x}-(n+1) c_{j}+c_{e}\right)^{2}}{(n+2)^{2}}
$$

The difference between the two is

$$
\Delta \pi_{i}-\Delta \pi_{j}=\frac{2\left(c_{j}-c_{i}\right)\left(A+\sum_{x=1}^{n} c_{x}-(n+1) c_{e}\right)}{(n+2)(n+1)}>0
$$

which has to be positive if the entrant is to produce a positive output.

ii) The proportional reduction in the profits of firm $i$ is

$$
\frac{\Delta \pi_{i}}{\pi_{i b}}=\frac{(n+1)^{2}}{\left(A+\sum_{x \neq i}^{n} c_{x}-n c_{i}\right)^{2}}\left[\frac{\left(A+\sum_{x \neq i}^{n} c_{x}-n c_{i}\right)^{2}}{(n+1)^{2}}-\frac{\left(A+\sum_{x \neq i}^{n} c_{x}-(n+1) c_{i}+c_{e}\right)^{2}}{(n+2)^{2}}\right]
$$

The proportional reduction in the profits of firm $\mathrm{j}$ is

$$
\frac{\Delta \pi_{j}}{\pi_{j b}}=\frac{(n+1)^{2}}{\left(A+\sum_{x \neq j}^{n} c_{x}-n c_{j}\right)^{2}}\left[\frac{\left(A+\sum_{x \neq j}^{n} c_{x}-n c_{j}\right)^{2}}{(n+1)^{2}}-\frac{\left(A+\sum_{x \neq j}^{n} c_{x}-(n+1) c_{j}+c_{e}\right)^{2}}{(n+2)^{2}}\right]
$$

Taking the difference between the two yields

$$
\frac{\Delta \pi_{i}}{\pi_{i b}}-\frac{\Delta \pi_{j}}{\pi_{j b}}=\frac{(n+1)^{2}}{(n+2)^{2}}\left[\frac{\left(A+\sum_{x \neq j}^{n} c_{x}-(n+1) c_{j}+c_{e}\right)^{2}}{\left(A+\sum_{x \neq j}^{n} c_{x}-n c_{j}\right)^{2}}-\frac{\left(A+\sum_{x \neq i}^{n} c_{x}-(n+1) c_{i}+c_{e}\right)^{2}}{\left(A+\sum_{x \neq i}^{n} c_{x}-n c_{i}\right)^{2}}\right]
$$

This expression is negative iff the term in brackets is negative. Taking the square roots of both terms in brackets and taking the difference yields

$$
\frac{\left(c_{i}-c_{j}\right)\left(A+\sum_{x=1}^{n} c_{x}-(n+1) c_{e}\right)}{\left(A+\sum_{x \neq i}^{n} c_{x}-n c_{i}\right)\left(A+\sum_{x \neq j}^{n} c_{x}-n c_{j}\right)}<0
$$


given that $\mathrm{c}_{\mathrm{i}}<\mathrm{c}_{\mathrm{j}}$.

Given the relationships between the profits/reservation profits of firms and their levels of efficiency, there are two effects which determine which firm will exit. First, because $\Delta \pi_{i}>\Delta \pi_{j}$ (lemma 1i), the absolute reduction in the profits of firm $i$ is larger, hence it has greater incentives to exit. Second, because $\Delta \pi_{\mathrm{i}} / \pi_{\mathrm{ib}}<\Delta \pi_{\mathrm{j}} / \pi_{\mathrm{jb}}$ (lemma 1ii), the proportional reduction in the profits of firm $\mathrm{j}$ is more important. Hence if reservation profits are a constant fraction of current profits for all firms, this makes exit by the inefficient firm more likely. This second effect facilitates the exit of inefficient firms.

Note that by assuming that $\bar{\pi}=0$ for all firms, the literature implicitly assumes that reservation profits of all firms are a constant fraction ( 0 ) of current profits, hence it is not surprising that inefficient firms are thought to exit first through competition, given that they suffer the largest proportional reduction in profits. Moreover, it is not equivalent to assume that $\bar{\pi}=0$ or $\bar{\pi}=\mathrm{k}>0$ for all firms, as in the latter case reservation profits are not a constant fraction of current profits.

We now state the main result of the paper, which links the reservation profits function $\bar{\pi}(\alpha, \mathrm{F})$ to the entry and exit decisions.

Proposition 1. Let reservation profits be given by $\bar{\pi}_{\mathrm{i}}=\alpha \pi_{\mathrm{ib}}-\mathrm{F}$, with $\alpha>0$ and $\mathrm{F}>0$, and let $\alpha$ and $\mathrm{F}$ be such that there are as few firms as possible, but at least one, such that $\pi_{\mathrm{ia}}=\bar{\pi}_{\mathrm{i}}$. Then, for a potential entrant of type e $\in\{\mathrm{e} 1, \mathrm{e} 2, \ldots, \mathrm{en}\}$ :

i) There exists n-1 thresholds $1>\alpha_{12}^{\mathrm{e}}>\alpha_{23}^{\mathrm{e}}>\ldots>\alpha_{\mathrm{n}-1, \mathrm{n}}^{\mathrm{e}}>0$ and n-1 thresholds $\mathrm{F}_{12}^{\mathrm{e}}>\mathrm{F}_{23}^{\mathrm{e}}>\ldots>\mathrm{F}_{\mathrm{n}-1, \mathrm{n}}^{\mathrm{e}}>0$ satisfying conditions ii through iv:

ii)

$$
\alpha_{i j}^{e}=\frac{\pi_{i \alpha}^{e}-\pi_{j a}^{e}}{\pi_{i b}-\pi_{j b}} \text { and } F_{i j}^{e}=\frac{\pi_{i a}^{e} \pi_{j b}-\pi_{i b} \pi_{j a}^{e}}{\pi_{i b}-\pi_{j b}}
$$

iii) $\alpha=\alpha_{\mathrm{ij}}^{\mathrm{e}}$ iff $\mathrm{F}=\mathrm{F}_{\mathrm{ij}}^{\mathrm{e}}$; 
iv) $\alpha_{\mathrm{ij}}^{\mathrm{e} 1}<\alpha_{\mathrm{ij}}^{\mathrm{e} 2}$ iff $\mathrm{c}_{\mathrm{e} 1}<\mathrm{c}_{\mathrm{e} 2}$;

v) and which determine the pattern of entry and exit as follows (with $i<j<k$ ) (subject to the exception mentioned in vi):

\begin{tabular}{|c|c|c|c|}
\hline when & $\alpha>\alpha_{12}^{\mathrm{e}}$ & the potential entrant enters and & firm 1 \\
\hline " & $\alpha<\alpha_{\mathrm{n}-1, \mathrm{n}}^{\mathrm{e}}$ & $"$ & firm $n$ \\
\hline " & $\alpha=\alpha_{i j}^{e}$ & $"$ & either firm $\mathrm{i}$ or firm $\mathrm{j}$ \\
\hline , & $\alpha_{j \mathrm{k}}^{\mathrm{e}}<\alpha<\alpha_{\mathrm{ij}}^{\mathrm{e}}$ & " & firm $j$ \\
\hline
\end{tabular}

vi) When $\mathrm{c}_{\mathrm{e}}=\mathrm{c}_{\mathrm{i}}$, where $\mathrm{i}$ is the firm that would exit under rule (v), no entry (and therefore no exit) occurs.

Proof.

ii, iii, and v) Let $i$ and $j$ be two adjacent firms, meaning that there is no firm with $\operatorname{cost} c \in\left[c_{i}, c_{j}\right]$. Firm i exits if $\pi_{\mathrm{ia}} \leq \bar{\pi}_{\mathrm{i}}$, i.e. if $\pi_{\mathrm{ia}} \leq \alpha \pi_{\mathrm{ib}}-$ F. Similarly, firm j exits if $\pi_{\mathrm{ja}} \leq \alpha \pi_{\mathrm{jb}}-\mathrm{F}$. Setting $\bar{\pi}$ as low as possible, and choosing $\alpha$ and $F$ such that these inequalities hold with equality for both firms $i$ and $j$, yields a system of two equations $\pi_{\mathrm{ia}}=\alpha \pi_{\mathrm{ib}}-\mathrm{F}$ and $\pi_{\mathrm{ja}}=\alpha \pi_{\mathrm{jb}} \mathrm{F}$ in two unknowns. Solving this system for $\alpha$ and F yields $\alpha_{\mathrm{ij}}^{\mathrm{e}}$ and $\mathrm{F}_{\mathrm{ij}}^{\mathrm{e}}$, where the superscript e indicates that post-entry profits depend on the type of the entrant. When $\alpha=\alpha_{\mathrm{ij}}^{\mathrm{e}}$ and $\mathrm{F}=\mathrm{F}_{\mathrm{ij}}^{\mathrm{e}}$, either firm i or firm $\mathrm{j}$ exits (but not both, because once one exits the other prefers to stay). The model cannot predict which firm will exit.

Starting from $\alpha=\alpha_{\mathrm{ij}}^{\mathrm{e}}$ and $\mathrm{F}=\mathrm{F}_{\mathrm{ij}}^{\mathrm{e}}$, we add $\epsilon_{\alpha}$ to $\alpha$ and $\epsilon_{\mathrm{F}}$ to $\mathrm{F}$, with $\epsilon_{\alpha<}{ }^{>} 0$ and $\epsilon_{\mathrm{F}<}>0$, always requiring that $\pi_{\mathrm{ia}}=\bar{\pi}_{\mathrm{i}}$ for at least one firm, to see how a change in $\alpha$ and $\mathrm{F}$ affects the pattern of exit. Firms' reservation profits become $\bar{\pi}_{\mathrm{i}}=\left(\alpha+\epsilon_{\alpha}\right) \pi_{\mathrm{ib}}-\left(\mathrm{F}+\epsilon_{\mathrm{F}}\right)$ and $\bar{\pi}_{\mathrm{j}}=\left(\alpha+\epsilon_{\alpha}\right) \pi_{\mathrm{jb}}-\left(\mathrm{F}+\epsilon_{\mathrm{F}}\right)$, respectively. For firm $\mathrm{i}$ to be the firm that exits, it must be that $\pi_{\mathrm{ia}}=\bar{\pi}_{\mathrm{i}}$ and $\pi_{\mathrm{ja}}>\bar{\pi}_{\mathrm{j}}$. This implies that $\epsilon_{\alpha} \pi_{\mathrm{ib}}-\epsilon_{\mathrm{F}}=0$ and $\epsilon_{\alpha} \pi_{\mathrm{jb}}-$ $\epsilon_{\mathrm{F}}<0$, which requires $\epsilon_{\alpha}>0$ and $\epsilon_{\mathrm{F}}>0$. Hence, starting from $\alpha=\alpha_{\mathrm{ij}}^{\mathrm{e}}$ and $\mathrm{F}=\mathrm{F}_{\mathrm{ij}}^{\mathrm{e}}$, an increase in $\alpha$ and $\mathrm{F}$ induces firm $i$ to exit, and firm $\mathrm{j}$ to stay. Given that firm $\mathrm{j}$ was chosen arbitrarily, it follows that any firm $\mathrm{x}$ with $\mathrm{c}_{\mathrm{x}}>\mathrm{c}_{\mathrm{i}}$ also prefers to stay.

For firm $\mathrm{j}$ to be the firm that exits, it must be that $\pi_{\mathrm{ia}}>\bar{\pi}_{\mathrm{i}}$ and $\pi_{\mathrm{ja}}=\bar{\pi}_{\mathrm{j}}$. This implies that $\epsilon_{\alpha} \pi_{\mathrm{ib}}-\epsilon_{\mathrm{F}}<0$ and $\epsilon_{\alpha} \pi_{\mathrm{jb}}-\epsilon_{\mathrm{F}}=0$, which requires $\epsilon_{\alpha}<0$ and $\epsilon_{\mathrm{F}}<0$. Hence, starting from $\alpha=\alpha_{\mathrm{ij}}^{\mathrm{e}}$ and $\mathrm{F}=\mathrm{F}_{\mathrm{ij}}^{\mathrm{e}}$, a decline in $\alpha$ and $F$ induces firm $j$ to exit, and firm $i$ to stay. Given that firm $i$ was chosen arbitrarily, it follows that any firm $\mathrm{x}$ with $\mathrm{c}_{\mathrm{x}}<\mathrm{c}_{\mathrm{j}}$ also prefers to stay. 
i)

$$
\begin{gathered}
F_{i j}^{e}-F_{j k}^{e}=\frac{2\left(c_{k}-c_{j}\right)\left(A+\sum_{x \neq j}^{n} c_{x}-n c_{j}\right)^{2}\left(A+\sum_{x=1}^{n} c_{x}-(n+1) c_{e}\right)}{(n+2)(n+1)\left[\left(A+\sum_{x \neq i}^{n} c_{x}-n c_{i}\right)+\left(A+\sum_{x \neq j}^{n} c_{x}-n c_{j}\right)\right]\left[\left(A+\sum_{x \neq j}^{n} c_{x}-n c_{j}\right)+\left(A+\sum_{x \neq k}^{n} c_{x}-n c_{k}\right)\right]}>0 \\
\alpha_{i j}^{e}-\alpha_{j k}^{e}=\frac{2(n+1)\left(c_{k}-c_{i}\right)\left(A+\sum_{x=1}^{n} c_{x}-(n+1) c_{e}\right)}{(n+2)\left[\left(A+\sum_{x \neq i}^{n} c_{x}-n c_{i}\right)+\left(A+\sum_{x \neq j}^{n} c_{x}-n c_{j}\right)\right]\left[\left(A+\sum_{x \neq j}^{n} c_{x}-n c_{j}\right)+\left(A+\sum_{x \neq k}^{n} c_{x}-n c_{k}\right)\right]}>0
\end{gathered}
$$

These two expressions are positive, given that $\mathrm{c}_{\mathrm{k}}>\mathrm{c}_{\mathrm{i}}$, and that the terms in brackets represent the numerators of firms' $i, j$ and $k$ outputs, which are positive.

Note that $\alpha_{\mathrm{ij}}<1$ iff $\pi_{\mathrm{ib}}-\pi_{\mathrm{ia}}>\pi_{\mathrm{jb}}-\pi_{\mathrm{ja}}$, which is true by lemma 1. Also, $\alpha_{\mathrm{ij}}>0$ because $\pi_{\mathrm{ia}}>\pi_{\mathrm{ja}}$ and $\pi_{\mathrm{ib}}>\pi_{\mathrm{jb}}$. The denominator of $\mathrm{F}_{\mathrm{ij}}$ is positive because $\pi_{\mathrm{ib}}>\pi_{\mathrm{jb}}$. The numerator is positive iff $\left(\pi_{\mathrm{ia}} / \pi_{\mathrm{ib}}\right)>\left(\pi_{\mathrm{ja}} / \pi_{\mathrm{jb}}\right)$, which is true by lemma 1 . Therefore $\mathrm{F}_{\mathrm{ij}}>0$.

iv)

$$
\alpha_{i j}^{e 1}-\alpha_{i j}^{e 2}=\frac{\pi_{i a}^{e 1}-\pi_{j a}^{e 1}}{\pi_{i b}-\pi_{j b}}-\frac{\pi_{i a}^{e 2}-\pi_{j a}^{e 2}}{\pi_{i b}-\pi_{j b}}=\frac{2\left(c_{e 2}-c_{e l}\right)\left(c_{i}-c_{j}\right)}{n+2}<0
$$

iff $\mathrm{c}_{\mathrm{e} 1}<\mathrm{c}_{\mathrm{e} 2}$.

vi) When $\mathrm{c}_{\mathrm{e}}=\mathrm{c}_{\mathrm{i}}$, where $\mathrm{i}$ is the firm that would exit under rule (v), we have that $\bar{\pi}_{\mathrm{e}}=\bar{\pi}_{\mathrm{i}}$ and $\pi_{\mathrm{ea}}=\pi_{\mathrm{ia}}$. Given that firm i would exit if e entered, we know that $\pi_{\mathrm{ia}}=\bar{\pi}_{\mathrm{i}}$. These equalities imply that $\pi_{\mathrm{ea}}=\bar{\pi}_{\mathrm{e}}$, which implies that e does not enter.

What remains to be proven is that if no entry occurs no firm would exit. If no entry occurs, the profits firms expect to realize in future Cournot competition are identical to those realized in the initial Cournot stage, given that the market conditions have not changed. Therefore it is sufficient to prove that $\pi_{\mathrm{ib}}>\bar{\pi}_{\mathrm{i}}$ for all firms to establish that if not entry occurs no firm would exit.

Let firm i be the only firm such that $\pi_{\mathrm{i} a}=\bar{\pi}_{\mathrm{i}}$. We know that for all other firms $\mathrm{j} \neq \mathrm{i}, \pi_{\mathrm{ja}}>\bar{\pi}_{\mathrm{j}}$. Given that $\pi_{\mathrm{xb}}>\pi_{\mathrm{xa}}$ for all $\mathrm{x}$, it follows that $\pi_{\mathrm{xb}}>\bar{\pi}_{\mathrm{x}}$ for all $\mathrm{x}$. The argument is essentially the same if there are 
two firms such that $\pi_{\mathrm{a}}=\bar{\pi}$.

Proposition 1 states that when $\alpha$ and F are very high, entry tends to crowd out the most efficient firm. As $\alpha$ and $\mathrm{F}$ decline, it is the second most efficient firm that exits (instead of the most efficient firm), and so on. When $\alpha$ and F are very low, entry tends to crowd out the highest cost firm. When the potential entrant is identical to the firm that would exit under that rule, no entry and no exit occur. There are critical levels of $\alpha$ and $F$ which determine which firm will exit. However, when $\alpha$ and $\mathrm{F}$ take exactly those critical values, the model predicts that one of two specific firms will exit, but cannot determine which of those two firms will. ${ }^{3}$ The higher is the cost of the entrant, the higher is the critical value of $\alpha$ that is necessary to induce the exit of a specific firm.

Remember that a firm with a higher cost has a lower post-entry profit than a firm with a lower cost. Also, note that $\alpha$ affects the absolute difference between firms' reservation profits, but does not affect the proportional difference between them. When $\alpha$ is low, the relation between current profits and reservation profits is weak, and reservation profits do not differ much between firms. The situation is not very different from the traditional context where all firms have equal reservation profits. In that case, reservation profits are very close across firms, but high cost firms are making lower profits following entry. Therefore, for the condition $\pi_{\mathrm{a}}=\bar{\pi}$ to be satisfied for as few firms as possible, it will be satisfied for high cost firms only. Therefore the firm with the highest cost exits. As $\alpha$ increases, the reservation profits of a low cost firm are increased more than the reservation profits of a high cost firm (because $\pi_{b}$ is higher for low cost firms). The condition $\pi_{\mathrm{a}}=\bar{\pi}$ is now satisfied for the firm with the second highest cost, and so on. Hence, when $\alpha$ takes intermediate values, it induces the exit of firms with intermediate costs. As $\alpha$ becomes very large, the reservation profits of low cost firms are significantly higher than the reservation profits of high cost firms, therefore the lowest cost firm exits.

Consider now the effect of $\mathrm{F}$, the fixed cost of changing markets. (Remember from lemma 1 that entry induces a larger proportional reduction in the profits of high cost firms.) F affects the proportional difference between firms' reservation profits, but does not affect the absolute

\footnotetext{
${ }^{3}$ Vettas (2000) studies the coordination of entry and exit through mixed strategies.
} 
difference between them. Moreover,

$$
\frac{\bar{\pi}}{\pi_{b}}=\frac{\alpha \pi_{b}-F}{\pi_{b}}=\alpha-\frac{F}{\pi_{b}}
$$

Therefore, when $\mathrm{F}$ is nil, reservation profits are a constant proportion of $\pi_{\mathrm{b}}$ for all firms. When $\mathrm{F}$ is low, the proportional differences in the ratio $\bar{\pi} / \pi_{\mathrm{b}}$ are not too important between firms, therefore the firms facing the highest proportional reduction in profits tend to exit first. When $\mathrm{F}$ is high, reservation profits represent an even higher proportion of $\pi_{b}$ for low cost firms (because $\pi_{b}$ is higher for low cost firms). In that case, even though low cost firms face a lower proportional reduction in profits, the very high ratio $\bar{\pi} / \pi_{\mathrm{b}}$ for them implies that they exit first. Therefore, the likelihood that inefficient firms crowd out efficient ones is greater when the fixed (independent of current profits) loss in profits due to leaving the market is larger.

When the cost of changing markets is high, the profits high cost firms would make on other markets are not sufficient to compensate for the cost of exiting the current market and entering an alternative market. At the same time, the low cost firm, because of transferable skills, can achieve high profits on the other market, and hence is more willing to exit the current market when competition intensifies. Whereas, when the cost of changing markets is low, the reduction in the profits of high cost firms induces them to leave the market; even though their alternative profits are low, they can afford to switch due to the low costs of changing markets. Efficient firms prefer to stay, i.e. they would not choose to exit before high cost firms have done so.

We see that the effects of $\alpha$ and F go in the same direction: a high $\alpha$ and a high F induce the exit of more efficient firms, while a low $\alpha$ and a low $\mathrm{F}$ induce the exit of less efficient firms.

Figure 1 illustrates the effect of $\alpha$ and $F$ in the $\alpha x F$ space with $n=3$. The figure presents the locus of combinations of $\alpha$ and $F$ such that $\bar{\pi}=\pi_{\mathrm{a}}$ for as few firms as possible, but for at least one. This translates into the exit of exactly one firm (except when the potential entrant is identical to the firm that would exit, in which case no exit occurs). When $\alpha>\alpha_{12}$ and $F>F_{12}$, firm 1 exits. When $\alpha=\alpha_{12}$ and $\mathrm{F}=\mathrm{F}_{12}$, either firm 1 or firm 2 exits. When $\alpha \in\left(\alpha_{12}, \alpha_{12}\right)$ and $\mathrm{F} \in\left(\mathrm{F}_{12}, \mathrm{~F}_{12}\right)$, firm 2 exits. When $\alpha=\alpha_{23}$ and $\mathrm{F}=\mathrm{F}_{23}$, either firm 2 or firm 3 exits. Finally, when $\alpha<\alpha_{23}$ and $\mathrm{F}<\mathrm{F}_{23}$, firm 3 exits. Along this schedule, exactly one firm exits; to the right (left) of the schedule more firms (respectively, no firm) 
exit.

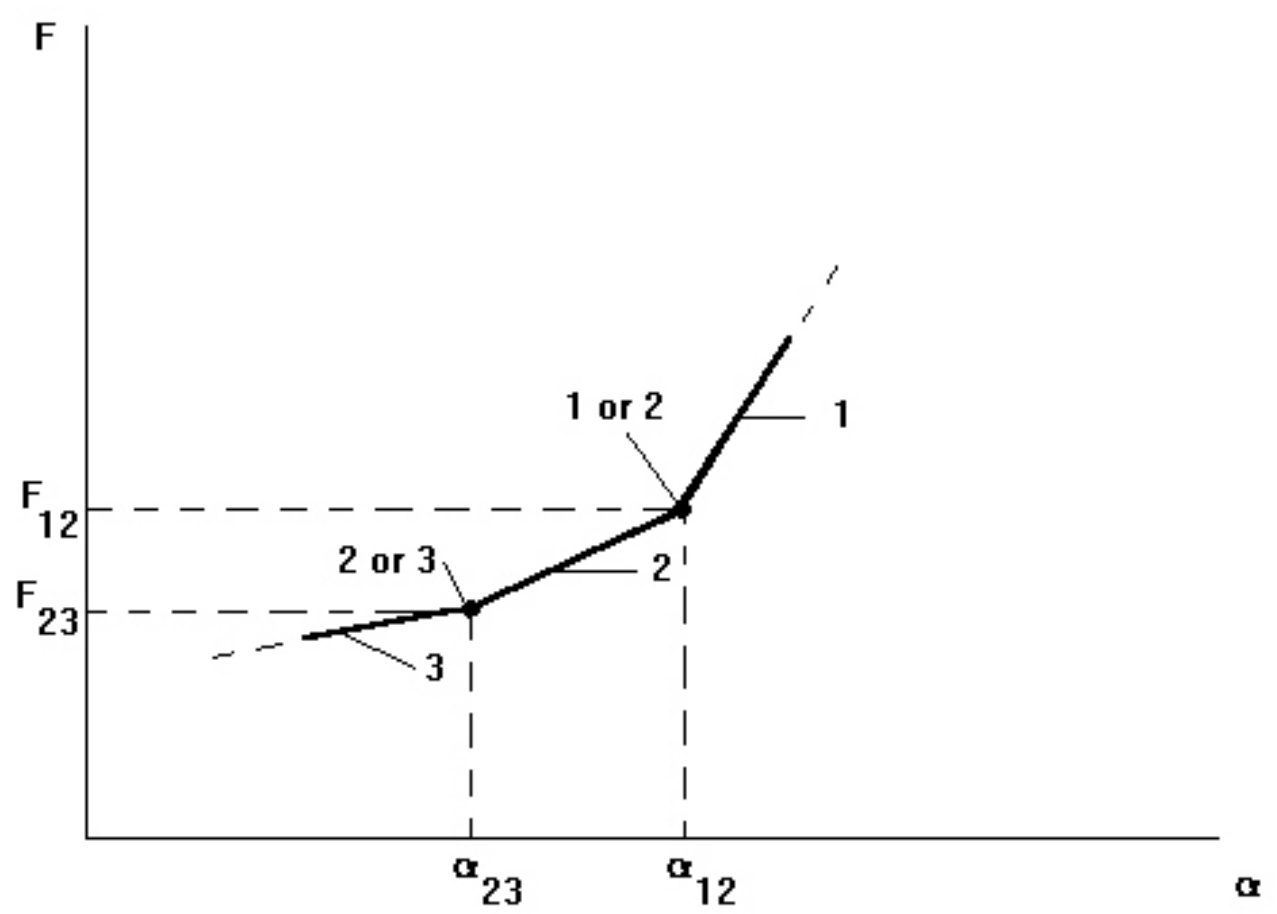

Figure 1 - Critical values of $\alpha$ and $F[n=3]$

To see how the endogenization of reservation profits affects firm selection, consider what would happen if all firms had $\bar{\pi}=\mathrm{k}$. In such a situation if entry is to induce the exit of some firm(s), it will be the least efficient firms that will exit first. We saw that when firms have different reservation profits, this does not necessarily occur. Moreover, the explicit modelling of reservation profits allows us to predict how they determine the pattern of exit.

Part iv of proposition 1 states that $\alpha_{i j}^{\mathrm{e} 1}<\alpha_{\mathrm{ij}}^{\mathrm{e} 2}$ : the critical $\alpha$ is higher when the entrant has a higher cost. ${ }^{4}$ We know that a low cost entrant reduces the profits of incumbents by a larger amount than a high cost entrant. Therefore, to induce the exit of a given firm, reservation profits have to be higher when facing a higher cost entrant. For instance, the likelihood that a low cost firm is crowded out is greater if the entrant is an intermediate cost firm than if the entrant is a high cost firm. This can have paradoxical welfare effects, where the benefits of increased competition are larger when

\footnotetext{
${ }^{4}$ The locus drawn in figure 1 was drawn for a given type of potential entrant. For a different potential entrant, a different locus would be drawn.
} 
this increased competition comes from high cost firms than from intermediate cost firms (in the standard model with zero opportunity costs, the opposite would obtain; high cost firms could reduce welfare even without inducing exit; see Khan and Yuan, 1999). This result points to the relationship between the identities of the entering and exiting firms. Whether more competition is desirable or not may depend on the type of potential entrant, and it is not always true that it is socially better to have a more efficient entrant.

Consider now part vi of proposition 1 , which states that when $c_{e}=c_{i}$, where $i$ is the firm that would exit under rule iv), no entry (and therefore no exit) occurs. Remember that there is exactly one incumbent which is identical to the potential entrant. If the firm that decides to exit is different from the incumbent, then the firm that is identical to the potential entrant has decided to stay, which implies that entry is profitable to the potential entrant. If, however, the firm that would exit if the incumbent entered is identical to the incumbent, this would mean that entry is not profitable to the incumbent, therefore no entry and no exit occur.

When the relation between reservation profits and efficiency is strong and the fixed costs of changing markets are high, either high cost firms crowd out efficient firms, or no entry occurs (the no entry case obtains when the potential entrant is a low cost firm). On the other hand, when the relation between reservation profits and efficiency is weak and the fixed costs of changing markets are low, either low cost firms replace high cost firms, or no entry occurs (the no entry case obtains when the potential entrant is a high cost firm).

We now see the usefulness of the assumption that no two incumbents are identical for simplifying the presentation of the results. From the definition of $\alpha_{\mathrm{ij}}$, it is clear that it would not be defined if $c_{i}=c_{j}$. In this case we would have to define the $\alpha$ s only for adjacent non-identical firms, which would complicate the presentation of the results without providing any additional insights.

The assumption that only one firm exits is less restrictive than it seems. Even if more than one firm were to exit, it would be firms with costs close to the firm predicted to exit by the model which would have greater incentives to exit.

The model indicates circumstances under which an intensification in competition can lead to the replacement of a low cost firm by a high cost one. When the market is sufficiently large, firms' fixed costs have no impact on the prevailing price. Therefore, the exit of an efficient firm 
following the entry of a less efficient one will result in an increase in prices and a decrease in welfare. The optimal level of competition is probably lower when skills are transferable than when all firms have equal reservation profits, especially when potential competition is represented by high cost firms.

Efficient and inefficient firms leave the market for different reasons. When $\alpha$ and $\mathrm{F}$ are low, the inefficient firms leave first because their profits are low, and the decline in their profits is greatest. When, on the other hand, $\alpha$ and $\mathrm{F}$ are high, efficient firms leave first, not because their profits are low, but because their opportunity costs are high.

Proposition 1 characterized the general result linking the type of potential entrant to the type of exiting firm (if any). In many cases we care most about whether entry increases the average efficiency in the industry, i.e. whether the entering firm is replacing a more or less efficient firm. While this result is incorporated into part $\mathrm{v}$ of Proposition 1, it is stated more clearly in the following corollary.

Corollary 1. A potential entrant of type j:

-crowds out a more efficient firm if $\alpha>\alpha_{\mathrm{ij}}$ and $\mathrm{F}>\mathrm{F}_{\mathrm{ij}}$; -crowds out a less efficient firm if $\alpha<\alpha_{\mathrm{jk}}$ and $\mathrm{F}<\mathrm{F}_{\mathrm{jk}}$.

\section{Proof.}

This result follows from Proposition 1.

Corollary 1 determines whether entry is going to increase or decrease the average level of efficiency in the industry. The interpretation is similar to the discussion following Proposition 1. However, the corollary points out to an important result of the model: even when an entrant crowds out a more efficient firm, it is not necessarily the most efficient firm among the incumbents that is crowded out. Similarly, when an entrant crowds out a less efficient firm, it is not necessarily the least efficient firm that exits. That is, the model does not say that high opportunity costs lead to the exit of the best, while low opportunity costs lead to the exit of the worse. Rather, any firm in the market can exit following entry, depending on the intensity of the relationship between current efficient and opportunity costs, and on the fixed costs of changing markets. 
While a priori any firm may exit following entry, the model indicates a tendency for the lowest cost firm and the highest cost firm to exit more often than intermediate firms. This is because the intervals $\left[\alpha_{\mathrm{n}-1, \mathrm{n}}, \alpha_{1,2}\right]$ and $\left[\mathrm{F}_{\mathrm{n}-1, \mathrm{n}}, \mathrm{F}_{1,2}\right]$ are very small. When $\alpha$ and $\mathrm{F}$ lie in those intervals, intermediate firms will exit. However, when $\alpha$ and $\mathrm{F}$ lie outside those intervals, the lowest cost firm or the highest cost firm will exit (depending on which side of the intervals $\alpha$ and F lie). To see this more clearly, consider the following two numerical parametrizations of the model. In both cases let $\mathrm{A}=1000$ and $\mathrm{c}_{\mathrm{i}}=\mathrm{i}$. In the first case let $\mathrm{n}=3$ and $\mathrm{c}_{\mathrm{e}}=2$, and in the second case let $\mathrm{n}=10$ and $\mathrm{c}_{\mathrm{e}}=5$. Table 1 presents the intervals $\left[\alpha_{n-1, n}, \alpha_{1,2}\right]$ and $\left[F_{n-1, n}, F_{1,2}\right]$ in both cases. We see that the intervals are very small, implying that for most admissible values of $\alpha$ and $\mathrm{F}$ (at least in the range of combinations inducing the exit of one firm), it will be the lowest cost firm (when $\alpha$ and $\mathrm{F}$ are high) or the highest cost firm (when $\alpha$ and $F$ are low) that will exit. In the examples taken here, the entrant has a cost that is close to the middle of the cost distribution of incumbents, but this result is true for all types of entrants. When the entry of any type of firm induces most often the exit of "extreme" firms, in the long run highly competitive industries will be populated mostly with intermediate cost firms.

Table 1 - Numerical examples of critical $\alpha s$ and Fs

\begin{tabular}{|lllll|}
\hline $\mathrm{n}=3$ & $\alpha_{2,3}=0.799598$ & $\alpha_{1,2}=0.800400$ & $\mathrm{~F}_{2,3}=9935$ & $\mathrm{~F}_{1,2}=9985$ \\
\hline $\mathrm{n}=10$ & $\alpha_{9,10}=0.902828$ & $\alpha_{1,2}=0.910984$ & $\mathrm{~F}_{9,10}=669$ & $\mathrm{~F}_{1,2}=737$ \\
\hline
\end{tabular}

$\alpha$ can also be seen as a measure of asset specialization. The lower $\alpha$, the less transferable skills are, the more specialized the assets to the current industry are, and the lower is the relation between current efficiency and reservation profits. Insofar as asset specialization can be a choice variable, $\alpha$ can be affected by the technological choice of the firm. In this case $\alpha$ can differ between firms. It could be that when the firm chooses a lower $\mathrm{c}$, it has to opt for a lower $\alpha$ : a more dedicated asset is more efficient, but less transferable to other activities. There is a similarity between the decisions firm face regarding the choice of flexibility of a technology (high fixed costs and low variable costs, or vice versa; flexibility can also be seen as the speed with which costs increase as we move away from the minimum efficient scale) and the transferability of skills (low $\mathrm{c}$ and low $\alpha$, or vice versa). Both flexibility of the technology and transferability of skills can be seen as strategic variables firms can affect. Moreover, there may be a link between the flexibility of the technology and its transferability. 
It is often said that modern technologies are more easily transferable from one activity to the other. The model predicts that this should translate into the exit of low-cost firms more often in the face of intensifying competition. Moreover, opportunity costs are likely to differ considerably from one industry to the other. Therefore similar entry threats can have different effects from one industry to the other.

\section{Conclusion}

The goal of this paper was to analyse the effect of the dependence of opportunity costs on current efficiency on the pattern of firm selection. In contrast with "technological" fixed costs which are often used as a proxy for opportunity costs, the explicit modelling of opportunity costs allows us to draw an economic relationship between them and current efficiency.

This problem was studied in the specific context of Cournot competition, where incumbents decided whether to stay in the market or to exit following entry. It was shown that entry by a firm may result in the exit of a more or a less efficient firm, depending on the relationship between current profits and opportunity costs. Namely, inefficient firms are more likely to crowd out efficient ones when the relationship between current profits and opportunity costs is steep, and when the fixed costs of changing markets are high. Situations where inefficient firms crowd out efficient ones are not pathological, but occur for a large range of plausible parameters of the model. Moreover, because the bounds of the critical parameter values (of the opportunity costs function) determining when entry crowds out the most efficient firm and the most inefficient firm form a small interval, the model predicts that in a dynamic setting firms with intermediate costs would crowd out the most efficient and the least efficient firms, resulting in a long term equilibrium where most of the remaining firms have "intermediate" levels of efficiency. Finally, entry can have paradoxical welfare effects, in that it may be preferable that a high cost firm enters rather than an intermediate cost firm; this is because the latter is more likely to crowd out a low cost firm.

The paper does not say that competition induces the exit of the fittest. Rather, it shows how any type of firm may exit following an intensification of competition, depending on the relationship between opportunity costs and efficiency, and on the type of entrant. Moreover, it identifies two important characteristics of the relationship, namely the strength of the correlation between current 
profits and opportunity costs, and the fixed cost of changing markets.

This research complements a number of modelling efforts which have aimed at identifying circumstances under which competition may not result in the survival of the fittest. Several dimensions of firms' behaviour and environment have been identified as important for selection: uncertainty about demand (Lippman et al., 1991), reentry costs (Londregan, 1986; Garella and Richelle, 1999), entry deterrence (Gromb et al., 1997), incomplete information about the rival's costs (Fudenberg and Tirole, 1986), probabilistic declines in demand (Fine and li, 1986; Li, 1986), the type of demand decline (Dierickx et al., 1991), capacity and plant size (Ghemawat and Nalebuff, 1985, 1990; Whinston, 1988; Reynolds, 1988). The paper shows that the transferability of skills can also affect firm selection. These models help explain the existing empirical evidence (Ghemawat and Nalebuff, 1990; Ghemawat, 1985; Libereman, 1990) indicating that in many industries the more efficient or the larger firms have suffered more form competition, or have closed more plants, than smaller firms.

In general the division of labour entails a low transferability of skills (or a high degree of specialization) between activities. While it is true that for a firm in a given sector, most other economic activities are deemed irrelevant as alternatives to their current operations, ${ }^{5}$ there are obvious cases where skills in one industry may be useful in another industry. The current profits of a firm in industry A may be positively correlated with its profits from moving to industry B, but negatively correlated with its profits from moving to industry C. Hence the model does not really go counter to the thesis of specialization and the division of labour. Rather, it takes into account technological similarities between market-unrelated industries.

The theory can also be applied to individuals. The degree of transferability of skills, from the point of view of the individual, diminishes as life progresses. Hence, a high school student has general skills that allows her to choose any field of study, while a university student in economics is unlikely to study or work outside the field of economics. Hence we can expect opportunity costs to have their fullest effect early in the individual's life: the most able students are unlikely to choose sectors where the supply of labour is abundant (even if they require high skills, e.g. high school

\footnotetext{
${ }^{5}$ Although conglomerates and multiproduct firms have shown that firms do enter into activities completely unrelated to their core products.
} 
teachers), and hence pay is limited. Rather, they will choose fields of study where there is less competition between workers (this is equivalent to the idea of no entry described above: efficient firms do not enter highly competitive markets). As the individual progresses in human capital accumulation and specialization, skills become less and less transferrable, and competition selects the fittest among those who have chosen a given field. But fields where competition is high will not have attracted the best candidates in the first place. Whether similar life-cycle considerations apply to firms is an open question, but the entrepreneur, at least early in her career, certainly specializes over time in the field in which she operates, and is likely to choose where to operate based on similar considerations.

The proposed research program has theoretical, empirical, as well as policy ramifications. Theoretically, the work would go against the conventional wisdom that competition leads to the survival of the fittest, and would induce a deeper reflection on the relation between reservation utility and efficiency.

From an empirical point of view, the paper sheds light on the empirical evidence discussed in the introduction showing that in some cases the best firms are not always those surviving competition. Moreover, by showing that competition can discourage very efficient firms from entering the market, the actual efficiency loss may be greater than what is measurable empirically. More generally, the empirical test of the model is how the firm's efficiency is related to the intensity of competition in the markets where it enters/exits, and how this relationship is affected by the transferability of skills (as proxied by the technology used, the qualifications required to perform operations in alternate markets, etc.)

The model focuses on the exit behaviour of firms and on the cost to an industry of losing an efficient incumbent. But the same analysis applies to potential entrants. When an efficient incumbent finds it profitable to leave the market, this means that an (identical) efficient potential entrant will not find it profitable to enter the market (because they have identical opportunity costs). Hence the cost can be expressed in terms of exit of an efficient incumbent, or in terms of the nonentry of an efficient potential entrant. One advantage of modelling the intensification of competition through entry (as I do here) rather than through declining demand (as most papers addressing selection do) is that the present modelization provides not only a theory of exit, but also a theory of 
entry, in addition to linking the entry decision with the exit decision.

In fact, because the model abstracts from some costs of exit, in some cases it may apply better to problems of entry. It is possible to argue that exit is costly as well as risky, and hence that efficient incumbents will adopt a number of strategies to fight entrants rather than to exit: product differentiation, entry barriers, innovation, are some examples (although the question remains of what happens when these strategies have been exhausted). However, these strategies are not available to an efficient potential entrant. Hence, intense competition may keep out efficient potential entrants, more easily than it induces exit by efficient incumbents. Therefore an alternative view of the model is that it provides a theory of (no) entry. A prediction of exit of a specific type of firm, is also a prediction of non-entry by a similar outsider. This aspect of the model is more difficult to test empirically, however, given that non-entry is by definition not observed.

From that perspective the model can also be used to analyse the location choices of MNEs. Given the relatively high mobility of MNEs, it can be assumed that they enjoy a high degree of transferability of skills: they can shift easily from one market to another. The model predicts not only that MNEs will choose low competition markets over high competition ones (as would any standard model of entry and exit predict), but that the best MNEs will enter (or not exit) the least competitive markets, while the worst MNEs will enter the most competitive ones. The same logic can be applied to multiproduct firms. Baden-Fuller (1989) and Lieberman (1990) find that diversified firms were more likely to close plants when industries declined.

Lastly, policymakers would be interested in determining circumstances under which increased competition can decrease the overall efficiency of the industry. The allowed concentration levels could be made contingent on the degree of transferability of skills. Welfare analysis becomes more complex, however, since the efficient firm exits one industry to enter another. When an efficient firm exits an industry in country A (because of stiff competition) and enters an industry in country B (where competition is softer), welfare in country A is unambiguously reduced.

When intense competition has prevailed in an industry for a long time, the best firms will have left that industry a long time ago, and the industry will be in a stationary state equilibrium with agents with intermediate or low levels of efficiency. The loss to that industry is invisible, because the best agents do not bother to enter. In the presence of transferable skills, perfect competition is 
no longer the ideal benchmark of market structure.

This points to an important difference between this model and the models studying the effects of declining industries on selection: those models focus on oligopolistic industries, while the present model applies to any market structure. The problem of inefficient selection may be found in concentrated as well as in highly competitive industries. Firms need not be multi-product or multi-plant, nor behave strategically, for inefficient selection to occur.

This modelization awaits further developments. The analysis was performed in a Cournot setting; it would be interesting to see how endogenous reservation profits interact with Bertrand competition. There is clearly a need for a better understanding of how reservation profits are related to current efficiency; in this paper an indirect link was established between the two through current profits, but a direct link between current costs and reservation profits would produce a more general model, especially if dynamics are to be incorporated. In this model the intensification of competition took the form of entry, however the analysis is easily extendable to intensified competition due to any other factor, such as a declining industry. Finally, the differences between technological fixed costs and opportunity costs need to be studied further. For instance, uncertainty about technological fixed costs is resolved after production, whereas uncertainty about reservation profits can be resolved only when the firm leaves the market.

\section{References}

Baden-Fuller, C. W. F., 1989, 'Exit from Declining Industries and the Case of Steel Castings', The Economic Journal, 99:949-61.

Dierickx, I., Matutes, C., Neven, D., 1991, 'Cost differences and survival in declining industries', European Economic Review, 35:1507-28.

Fine, C., and Li, L., 1986, Equilibrium Exit in Stochastically Declining Industries, MIT Sloan School Working Paper No. 1804-86.

Garella, P.G., and Richelle, Y., 1999, 'Exit, sunk costs and the selection of firms', Economic Theory, 13:643-70.

Ghemawat, P., 1984, ‘The Exit Decision', Graduate School of Business Administration, Harvard University, Working Paper 1-784-065. 
Ghemawat, P., and Nalebuff, B., 1985, 'Exit', RAND, 16(2):184-94.

Ghemawat, P., and Nalebuff, B., 1990, ‘The Devolution of Declining Industries', Quarterly Journal of Economics, 105(1):167-86.

Gromb, D., Ponssard, J.P., and Sevy, D., 1997, 'Selection in Dynamic Entry Games', Games and Economic Behavior, 21:62-84.

Huang, C., and Li, L., 1986, Continuous Time Stopping Games, MIT Sloan School, Mimeo.

Khan, H., and Yuan, L., 1999, Technology Heterogeneity, Competition and Social Efficiency, Presented at the $33^{\text {rd }}$ Annual Meeting of the Canadian Economics Association, Toronto.

Libereman, M., 1990, 'Exit from Declining Industries: “Shakeout” or “Stakeout”?', RAND, 21(4):538-54.

Lippman, S.A., Mccardle, K.F., and Rumelt, R.P., 1991, 'Heterogeneity under Competition', Economic Inquiry, 29:774-82.

Londregan, J., 1986, Entry and Exit over the Industry Life-Cycle, Princeton University, Mimeo.

Reynolds, S. S., 1988, 'Plant Closings and Exit Behaviour in Declining Industries', Economica, 55:493-503.

Vettas, N., 2000, 'On entry, exit, and coordination with mixed strategies', European Economic Review, 44:1557-76.

Whinston, M. D., 1988, 'Exit with multiplant firms', RAND, 19(4):568-88. 